\title{
Profil dan Temuan Klinis Pasien Perdarahan Saluran Cerna di Departemen Kesehatan Anak RSUP Dr. Sardjito 2009 - 2015
}

Galih Akbar Pinandhito, Titis Widowati, Wahyu Damayanti

Departemen Ilmu Kesehatan Anak Fakultas Kedokteran Universitas Gadjah Mada/RSUP Dr. Sardjito, Yogyakarta

Latar belakang. Perdarahan saluran cerna pada anak merupakan salah satu tanda bahaya sehingga diagnosis dan pengobatan dini sangat penting.

Tujuan. Mengetahui etiologi dan temuan klinis perdarahan saluran cerna anak yang dirawat di RSUP Dr. Sardjito.

Metode. Penelitian retrospektif menggunakan rekam medis pasien anak berusia kurang dari 18 tahun yang menjalani endoskopi dan kolonoskopi karena perdarahan saluran cerna dari Januari 2009 hingga Juni 2015. Data rekam medis yang tidak lengkap tidak diikutkan sertakan dalam penelitian.

Hasil. Dari 55 pasien yang memenuhi syarat, terdapat 27 (49\%) pasien perdarahan saluran cerna atas dan 28 (51\%) pasien perdarahan saluran cerna bawah. Varises esofagus adalah etiologi terbanyak perdarahan saluran cerna atas 10 (37\%), sedangkan untuk perdarahan saluran cerna bawah adalah kolitis 17 (60\%). Perdarahan saluran pada anak lebih sering terjadi pada perempuan usia 1-6 tahun 29 (53\%). Gejala yang lebih sering terjadi yaitu hematemesis 13 (24\%) dan hematokezia 27 (49\%). Keluhan perdarahan saluran cerna atas terbanyak adalah nyeri perut $13(48 \%)$ sedangkan saluran cerna bawah adalah diare $8(29 \%)$. Anemia berat ditemukan pada 5 (19\%) pasien perdarahan saluran cerna atas dan 1 (4\%) pasien perdarahan saluran cerna bawah.

Kesimpulan. Varises esofagus merupakan penyebab tersering perdarahan saluran cerna atas sedangkan saluran cerna bawah adalah kolitis. Anak yang datang dengan keluhan nyeri perut dan diare harus dipikirkan salah satu penyebabnya adalah perdarahan saluran cerna. Sari Pediatri 2017;19(4):196-200

Kata kunci: perdarahan saluran cerna anak, endoskopi, kolonoskopi

\section{Patients with Gastro-Intestinal Bleeding in The Departement of Child Health Sardjito Hospital from 2009 - 2015: Profile and Clinical Findings}

Galih Akbar Pinandhito, Titis Widowati, Wahyu Damayanti

Background. Gastro-intestinal (GI) bleeding is an alarming symptom for patients of any age. Early diagnosis and treatment are essential. Objective. To study the etiology and clinical findings of GI bleeding in children hospitalized at Sardjito Hospital.

Methods. We restrospectively reviewed medical records of pediatric patients aged less than 18 years who underwent endoscopy and colonoscopy due to GI bleeding from January 2009 to June 2015. Those with incomplete data were excluded.

Results. Out of 55 eligible patients, there were 27 (49\%) upper and 28 (51\%) lower GI bleeding. Esophageal varices in 10 (37\%) patient was the most common etiology of upper GI bleeding, whereas lower GI bleeding was colitis 17 (60\%). Girls predominated in upper and lower GI bleeding with a proportion of $14(52 \%)$ and $15(54 \%)$, respectively. Both upper and lower GI bleeding predominantly occurred in children aged 1-6 years $13(48 \%)$ and $16(57 \%)$. Hematemesis in 13 (24\%) and hematochezia in 27 (49\%) patient were the most frequent symptoms. The most prevalent complaint were abdominal pain in upper $13(48 \%)$ and diarrhea in lower GI bleeding 8 (29\%). Severe anemia was found in 5 (19\%) patients with upper and 1 (4\%) patients in lower GI bleeding. Conclusion. Esophageal varices and colitis are the most prevalent etiology of GI bleeding in children. Children come with abdominal pain and diarrhea should be considered as one of the causes of GI bleeding. Sari Pediatri 2017;19(4):196-200

Keywords: gastrointestinal bleeding, children, endoscopy, colonoscopy

Alamat korespondensi: Dr. Galih Akbar Pinandhito. Peserta Program Pendidikan Dokter Spesialis Ilmu Kesehatan Anak, Departemen Ilmu Kesehatan Anak FK UGM-RSUP Dr. Sardjito, Jl. Kesehatan No.1 Sekip Yogyakarta 55284 E-mail: g.akbar.p@gmail.com 
$\mathrm{P}$ erdarahan saluran cerna meskipun dalam jumlah sedikit, dapat menyebabkan ketakutan pada anak serta kecemasan pada orang tua. Perdarahan dapat terjadi di manapun sepanjang saluran cerna. Kondisi tersebut berpotensi menyebabkan kegawatan yang mengancam jiwa. Berdasarkan data Nationwide Emergency Department tahun 2006 hingga 2011, dari 450.000 pasien kegawatan anak 20\% datang dengan perdarahan saluran cerna atas dan 30\% datang dengan perdarahan saluran cerna bawah. Insiden terbanyak adalah anak berusia $11-15(50,8 \%)$ tahun dan anak perempuan lebih banyak daripada laki-laki $(54,5 \%$ vs $45,5 \%)$. Terjadi juga peningkatan jumlah pasien perdarahan saluran cerna dari 82,18 per 100.000 anak pada tahun 2006 menjadi 93,30 per 100.000 anak pada tahun $2011 .{ }^{1}$ Mortalitas dari perdarahan saluran cerna atas pada anak $4,8 \%,{ }^{2}$ sedangkan saluran cerna bawah $0,6 \% .^{3}$

Endoskopi dan kolonoskopi merupakan prosedur diagnostik untuk mengetahui etiologi perdarahan saluran cerna atas dan bawah. Selain terbatas, ketersediaan alat hanya dimiliki oleh rumah sakit pusat rujukan. Pengenalan sedini mungkin penyebab perdarahan saluran cerna pada anak melalui gejala klinis dan pemeriksaan fisik sangat penting untuk mempertimbangkan perujukan pasien. Penegakan diagnosis dan penanganan sesegera mungkin dapat mengurangi morbiditas dan mortalitas perdarahan saluran cerna.

Tujuan penelitian ini adalah untuk mengetahui profil dan klinis pasien anak usia kurang dari 18 tahun dengan perdarahan saluran cerna di Departemen Ilmu Kesehatan Anak RSUP Dr. Sardjito.

\section{Metode}

Tabel 1. Karakteristik dasar subyek penelitian

\begin{tabular}{lcc}
\hline Karakteristik dasar & $\begin{array}{c}\text { Perdarahan saluran cerna atas } \\
\mathrm{n}=27,(\%)\end{array}$ & $\begin{array}{c}\text { Perdarahan saluran cerna bawah } \\
\mathrm{n}=28,(\%)\end{array}$ \\
\hline Jenis kelamin & $13(48)$ & $13(46)$ \\
$\quad$ Laki-laki & $14(52)$ & $15(54)$ \\
Perempuan & & \\
Usia (tahun) & 0 & $1(4)$ \\
$<1$ & $13(48)$ & $16(57)$ \\
$1-6$ & $6(23)$ & $4(14)$ \\
$6-12$ & $8(29)$ & $7(25)$ \\
$12-18$ & & \\
\hline
\end{tabular}

Sari Pediatri, Vol. 19, No. 4, Desember 2017

Penelitian deskriptif retrospektif dilakukan dengan menggunakan rekam medis pasien anak usia kurang dari 18 tahun yang terdiagnosis perdarahan saluran cerna atas atau bawah serta telah dilakukan tindakan endoskopi/kolonoskopi dari bulan Januari 2009 hingga Juni 2015. Data rekam medik yang tidak lengkap dikeluarkan dari penelitian. Data disajikan dalam bentuk deskriptif proporsi jumlah dan persentase mengenai jenis kelamin, usia, keluhan saat masuk rumah sakit, hasil endoskopi atau kolonoskopi, keluhan penyerta, dan kadar hemoglobin pada saat masuk rumah sakit.

\section{Hasil}

Dari Januari 2009 hingga Juni 2015 terdapat 88 pasien anak $<18$ tahun yang dilakukan endoskopi/ kolonoskopi karena perdarahan saluran cerna di RSUP Dr. Sardjito. Setelah dilakukan eksklusi tersisa 55 subyek yang memenuhi kriteria. Data mengenai karakteristik dasar penelitian tertera pada Tabel 1.

Pada penelitian ini didapatkan 27 (49\%) pasien dengan perdarahan saluran cerna atas dan 28 (51\%) pasien dengan perdarahan saluran cerna bawah. Perdarahan saluran cerna atas dan bawah didominasi oleh anak perempuan daripada anak laki-laki ( 52\% dan 54\%). Kelompok anak usia 1-6 tahun paling banyak mengalami perdarahan saluran cerna atas (48\%) dan bawah (57\%). Hematemesis (48\%) merupakan keluhan utama terbanyak perdarahan saluran cerna atas yang menyebabkan pasien datang ke rumah sakit, sedangkan pada perdarahan saluran cerna bawah terbanyak adalah hematokesia (96\%). Adapun keluhan terbanyak yang menyertai pasien pada perdarahan saluran cerna atas adalah nyeri perut 
Galih Akbar Pinandhito dkk: Profil dan temuan klinis pasien perdarahan saluran cerna
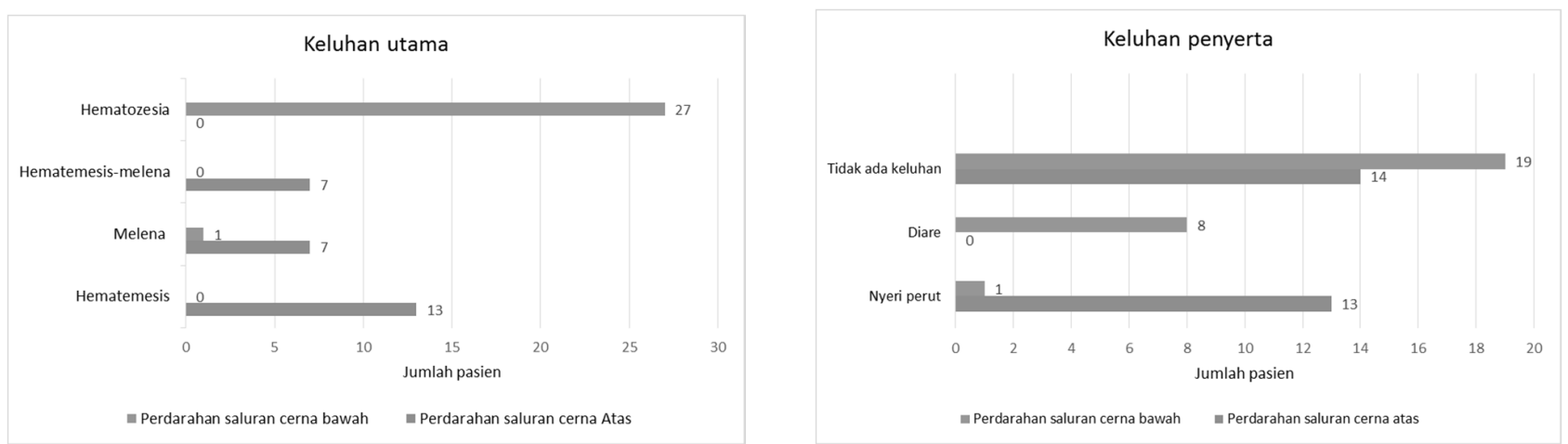

Gambar 1. Keluhan utama dan penyerta pasien

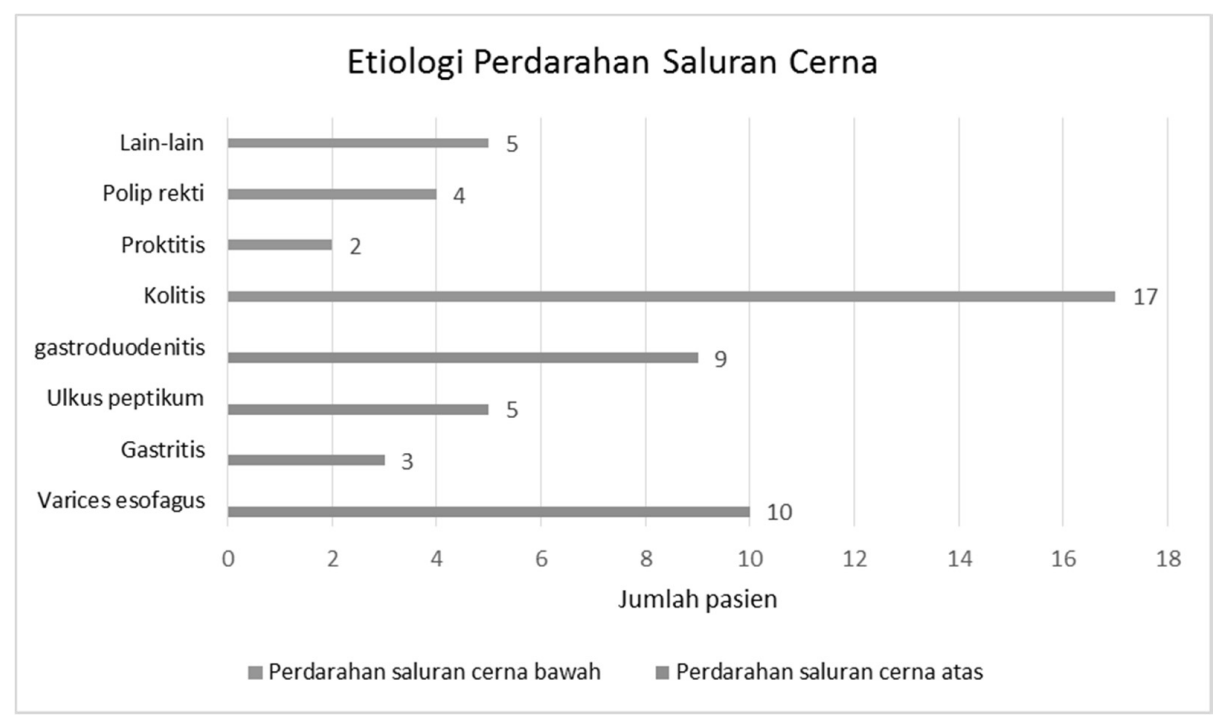

Gambar 2. Etiologi perdarahan saluran cerna

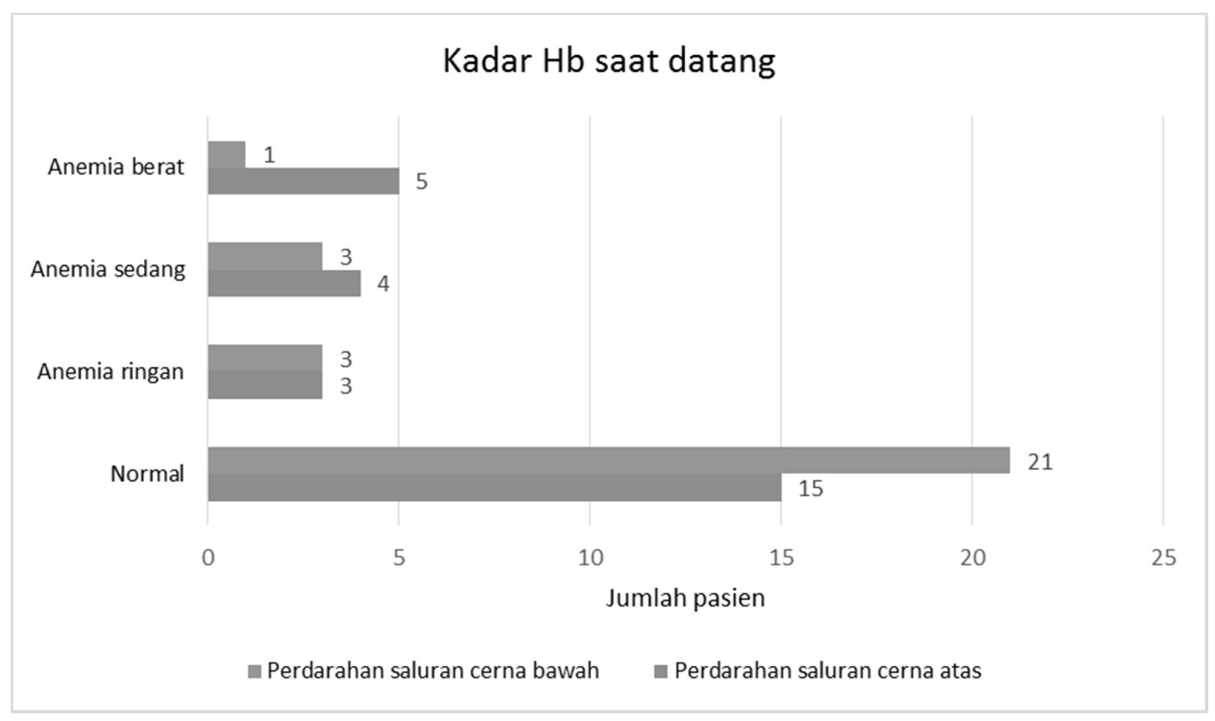

Gambar 3. Kadar Hb saat datang 
(48\%), keluhan diare (29\%) banyak menyertai pasien perdarahan saluran cerna bawah. Profil perdarahan saluran cerna atas dan perdarahan saluran cerna bawah tertera pada Gambar 1.

Hasil dari endoskopi dan kolonoskopi menunjukkan bahwa varises esofagus (37\%) adalah etiologi paling banyak terjadi pada perdarahan saluran cerna bagian atas, sedangkan saluran cerna bagian bawah etiologi terbanyak adalah kolitis (60\%). Etiologi perdarahan saluran cerna ditampilkan pada Gambar 2.

Gejala klinis lain yang ditemukan yaitu adanya kondisi anemia berat yang ditemukan pada 5 (19\%) pasien perdarahan saluran cerna atas pada saat datang ke rumah sakit. Satu pasien dengan perdarahan saluran cerna bawah juga ditemukan dengan kondisi tersebut. Kadar $\mathrm{Hb}$ saat pasien datang ke rumah sakit ditampilkan pada Gambar 3.

\section{Pembahasan}

Perdarahan saluran cerna pada anak paling sering dialami oleh anak perempuan. Hasil tersebut sesuai dengan laporan penelitian serupa di Perancis, ${ }^{6}$ Saudi Arabia, ${ }^{5}$ dan Nepal. Berbeda dengan penelitian di Baghdad $^{8}$ dan $\operatorname{Iran}^{7}$ yang melaporkan bahwa anak lakilaki lebih sering menderita perdarahan saluran cerna dibanding perempuan.

Kejadian perdarahan saluran cerna paling sering diderita anak usia 1 sampai 6 tahun. Hasil tersebut serupa dengan laporan Hassoon, ${ }^{8}$ Dehghanie, ${ }^{7}$ Zahmatkeshan, ${ }^{9}$ dan Khusdil. ${ }^{10}$ Sebagian besar ulasan tentang perdarahan saluran cerna anak terfokus pada diagnosis berdasarkan kelompok usia, tetapi etiologi dari perdarahan saluran cerna belum dapat ditegakkan hanya berdasarkan hal tersebut ${ }^{11}$. Pembagian kelompok usia cukup penting untuk menentukan diagnosis banding sehingga mempersempit jenis etiologi perdarahan saluran cerna pada anak.

Tigabelas (48\%) anak mengalami hematemesis dan 27 (96\%) anak mengalami hematozesia. Penelitian Gimiga $^{12}$ dan Huang ${ }^{13}$ juga melaporkan hasil serupa. Penelitian Hossein ${ }^{14}$ mencatat hematozesia (54,4\%) sebagai gejala terbanyak pada perdarahan saluran cerna bawah. Hematemesis dinilai lebih mengkhawatirkan dan menakutkan bagi orang tua dibandingkan gejala perdarahan saluran cerna lainnya. Hal tersebut yang menyebabkan orang tua segera membawa anaknya ke rumah sakit untuk penanganan lebih lanjut., ${ }^{5}$
Nyeri perut sebagai gejala penyerta perdarahan saluran cerna atas ditemukan 48\%, sedangkan diare tercatat $29 \%$. Penelitian Javid ${ }^{15}$ di India melaporkan $36 \%$ pasien perdarahan saluran cerna atas mengeluhkan nyeri perut. Ojuawo $\mathrm{dkk}^{16}$ melaporkan diare dan nyeri perut sebagai gejala penyerta terbanyak perdarahan saluran cerna bawah. Gejala nyeri perut yang dirasakan pasien dapat disebabkan adanya lesi di mukosa saluran cerna sehingga terjadi perdarahan lokal. ${ }^{5,13}$ Lesi yang semakin meluas menyebabkan nyeri perut semakin memberat. Adanya diare dan perdarahan melalui dubur kemungkinan terjadi karena kolitis yang disebabkan infeksi. ${ }^{23}$ Infeksi pada saluran cerna dianggap sebagai penyebab terbanyak perdarahan saluran cerna bawah dan disentri. ${ }^{17}$

Berdasarkan hasil endoskopi dan kolonoskopi, etiologi terbanyak perdarahan saluran cerna atas adalah varices esofagus (37\%). Hasil tersebut serupa dengan penelitian di negara timur tengah dan India yang melaporkan bahwa 35\%-40\% etiologi perdarahan saluran cerna atas adalah varises esofagus. ${ }^{4,8,18,19}$ Secara global, etiologi perdarahan saluran cerna atas pada anak bervariasi tergantung populasi, letak geografis, dan komorbid dari pasien. ${ }^{19,20}$ Varises esofagus banyak terjadi di negara Timur Tengah dan Asia, sedangkan di Amerika Utara ulkus peptikum menjadi etiologi terbanyak. ${ }^{20}$ Penyebab varises esofagus di negara berkembang kemungkinan berhubungan dengan tingginya penyakit hati, hepatitis $B$, dan riwayat sepsis pada masa neonatus. Di negara maju, penyebab terbanyak ulkus peptikum adalah infeksi Helicobacter pylori. Kolitis (60\%) merupakan etiologi terbanyak dari perdarahan saluran cerna bawah. Systematic review oleh Bai $\mathrm{dkk}^{21}$ menyimpulkan 3 penyebab terbanyak perdarahan saluran cerna bawah pada anak di negara Cina adalah polip kolorektal (49\%), kolitis (11\%), dan intususepsi (9\%).Pada populasi negara barat dilaporkan $17 \%-40 \%$ pasien anak mengalami perdarahan saluran cerna bawah, penyebabnya adalah diverticulitis. ${ }^{22}$ Perbedaan etiologi perdarahan saluran cerna anak antara negara timur dan barat tidak dijelaskan dalam penelitian.

Penelitian ini mendapatkan 5 (19\%) anak dengan perdarahan saluran cerna atas dan $1(4 \%)$ anak dengan perdarahan saluran cerna bawah datang ke rumah sakit dalam kondisi anemia berat. Perdarahan masif pada saluran cerna bagian atas dapat menyebabkan hemodinamik terganggu hingga pasien jatuh dalam keadaan syok. Ruptur varises esofagus merupakan 
penyebab tersering perdarahan masif yang dapat menyebabkan anemia berat. ${ }^{15,24}$ Perdarahan saluran cerna bawah pada anak seringkali dapat sembuh dengan sendirinya tanpa pengobatan dan jarang sekali menyebabkan gangguan hemodinamik. ${ }^{11}$ Kondisi anemia berat pada pasien perdarahan saluran cerna bawah dapat diakibatkan karena adanya perdarahan occult bercampur feses yang telah berlangsung lama.

\section{Kesimpulan}

Varises esofagus merupakan penyebab tersering perdarahan saluran cerna atas dan kolitis padan saluran cerna bawah. Anak yang datang dengan keluhan nyeri perut dan diare perlu dipikirkan kemungkinan salah satu penyebabnya adalah perdarahan saluran cerna.

\section{Daftar pustaka}

1. Pant C, Olyaee M, Sferra TJ, dkk. Emergency department visits for gastrointestinal bleeding in children: results from the Nationwide Emergency Department Sample 2006-2011. Curr Med Res Opin 2015;31:347-51.

2. Cochran EB, Phelps SJ, Tolley EA, Stidham GL. Prevalence of, and risk factors for, upper gastrointestinal tract bleeding in critically ill pediatric patients. Crit Care Med 1992;20:1519-23.

3. Kollef MH, O'Brien JD, Zuckerman GR, dkk. BLEED: a classification tool to predict outcomes in patients with acute upper and lower gastrointestinal hemorrhage. Crit Care Med 1997; 25:1125-32.

4. Sawsan I. AL Azzawi. the role of endoscopy in the differential diagnosis of upper gastrointestinal bleeding in children. IPMJ 2004;3:393.

5. EL Mouzan MI, Abdullah AM, AI Mofleh IA. Yield of endoscopy in children with hematemesis. Trop Gastroenterol 2004;25:44-6.

6. Lacroix J, Nadeau D, Laberge S, Gauthier M, Lapierre G, Farrell CA. Frequency of upper gastrointestinal bleeding in a pediatric intensive care unit. Crit Care Med 1992;20:35-42.

7. Dehghani SM, Haghighat M, Imanieh MH, Tabebordbar MR Upper Gastrointestinal Bleeding in Children in Southern Iran. Indian J Pediatr 2009; 76:635-8.

8. Hassoon JB, Al-Maeeni AA, Matloub HY. Upper gastrointestinal bleeding in children. J Fac Med Baghdad 2012;54:223-7

9. Zahmatkeshan M, Fallahzadeh E, Najib K, dkk. Etiology of lower gastrointestinal bleeding in children: a single center experience from southern iran. Middle East J Dig Dis 2012;4:216-23.

10. Khushdil A, Ali S, Malik R, Farrukh H. Etiology of lower gastrointestinal bleeding in paediatric patients, a colonoscopic surgery. Pak Armed Frces Med J 2014;64:484-7.

11. Boyle JT. Gastrointestinal bleeding in infant and children. Pediatr Rev 2008; 29:39-52.

12. Gimiga N, Diaconescu S, Olaru C, dkk. Etiologi of gastrointestinal bleeding in children. Rev Rom de Pediat 2015;LXIV:28-33.

13. Huang IF, Wu TC, Wang KS. dkk. Upper gastrointestinal endoscopy in children with upper gastrointestinal bleeding. J Chin Med Assoc 2003; 66:271-5.

14. Hossein M, Dehghani SM, Nikzadeh H, Malekpour A. Lower Gastrointestinal Bleeding in Children: Experiences From Referral Center in Southern Iran. J Compr Ped 2013;3:115-8.

15. Javid G, Zarger SA, Wani MA, dkk. Upper gastrointestinal bleeding in children in Kashmir (India): an analysis of cause, characteristics and outcome. J Dig Endosc 2010:1:145-50.

16. Ojuawo A, St Louis D, Lindley KJ, Milla PJ. Non-infective colitis in infancy: evidence in favour of minor immunodeficiency in its pathogenesis. Arch Dis Child 1997;76: 345-8.

17. Leung AK, Wong AL. Lower gastrointestinal bleeding in children. Pediatr Emerg Care 2002;18:319-23.

18. Mittal SK, Kalra KK, Aggarwal V. Diagnostic upper GI endoscopy for hemetemesis in children: experience from a pediatric gastroenterology centre in north India. Indian J Pediatr 1994;61:651-4.

19. Yachha SK, Khanduri A, Sharma BC, Kumar M. Gastrointestinal bleeding in children. J Gastroenterol Hepatol 1996;11:903-7.

20. Cleveland K, Ahmad N, Bishop P, Nowicki M. Upper gastrointestinal bleeding in children: an 11 year retrospective endoscopic investigation. World J Pediatr 2012;8:123-8.

21. Yu Bai, Jun Peng, Jun Gao, Duo-Wu Zou, Zhao-Shen Li. Epidemiology of lower gastrointestinal bleeding in China:Single-center series and systematic analysis of Chinese literature with 53951 patients. J Gastroenterol and Hepatol 2011;26:678-82.

22. Zuckerman GR, Prakash Ch. Acute lower intestinal bleedingPart II: Etiology, therapy, and outcomes. GI Endoscopy 1999;49 228-38.

23. Kay M, Wyllie R: Gastrointestinal hemorrhage. Dalam: Pediatric Gastrointestinal Disease Pathophysiology/Diagnosis/ Management. Edisi ke-3. Wyllie R, Hyams JS, penyunting. WB Saunders Co PA, USA; 2006.h. 203-15.

24. Hassal E. Nonsurgical treatments for portal hypertension in children. Gastrointest Endosc Clin Nort Am 1994; 4:22358. 